\title{
De las circunstancias en la anamnesis
}

\section{Circumstances of anamnesis}

\author{
Eugenio Matijasevic • Bogotá D.C. (Colombia)
}

Hace algún tiempo una empresa administradora de fondos de inversión me hizo llegar una invitación (que decliné) a una reunión publicitaria sobre los supuestos beneficios de acogerse a su égida. Lo único llamativo de la invitación era el formato de la misma: de manera muy metódica y precisa especificaba punto por punto la información concerniente a la reunión propuesta mediante el recurso de un listado de seis ítems en el que la primera palabra de cada uno era una pregunta realizada mediante un pronombre interrogativo o un adverbio interrogativo o una locución adverbial, acompañada al frente por la respuesta. El conjunto de preguntas (¿quiénes?, ¿qué?, ¿dónde?, ¿cuándo?, ¿cómo? y ¿por qué?) y sus respectivas respuestas permitía conocer en detalle, en su orden, los invitados a la reunión, el nombre de la empresa que invitaba, el lugar, el momento (la fecha y la hora), los requisitos (y restricciones) para asistir y el propósito de la misma.

Parece ser que en diversas escuelas de administración de negocios Colombianas estaban enseñando por entonces esa secuencia de preguntas, $u$ otra secuencia parecida, como regla mnemotécnica para que el encargado de garantizar la culminación de un determinado proceso o tarea, bien fuera una reunión tan sencilla como a la que me habían invitado o el desarrollo de una gran empresa, estableciera de manera clara y precisa las metas de dicho proceso. Las preguntas en cuestión, tomadas de publicaciones periódicas y de libros y norteamericanos sobre management, formaban parte de un "protocolo" o "método" más amplio conocido como SMART Goals, en donde SMART es un acrónimo para specific, measurable, asignable, realistic y time-related. De acuerdo con George T. Doran, quien creó el acrónimo en 1981 (1), son estas las características que debe reunir cualquier objetivo que tenga sentido (“How do you write meaningful objectives?"). Parece ser que los criterios básicos para la puesta a punto de una meta gerencial especificados en el acrónimo ya habían sido desarrollados casi tres décadas antes por Peter Drucker, a quien podríamos llamar el padre del estilo gerencial corporativo en Norteamérica, en su libro The Practice of Management (2), pero nunca nadie antes de Doran los había sintetizado de manera tan precisa en un acrónimo tan fácil de recordar.

En el marco de los criterios SMART para establecer y describir un objetivo, Doran había dejado definida la especificidad de la meta, la S de SMART, como el paso inicial en el que había que apuntar a un área de desarrollo específica, precisa, bien delimitada ("target a specific area for improvement"). Durante las dos décadas siguientes, las últimas del siglo XX, la especificidad de Doran sería redefinida de una manera bastante divergente de la postulada por él y todos los libros de texto sobre gerencia corporativa de la época comenzarían a difundir al unísono, sin que sea posible establecer un único autor, la nueva definición: la descripción de una meta es específica cuando es capaz de dar respuesta a las seis preguntas W ("the six W questions"): Who: ¿quiénes participan?, What: ¿qué se quiere lograr?, Where: ¿en dónde?, When: ¿en qué momento?, Which: ¿cuáles son los requisitos y restricciones?, Why: ¿qué razones precisas, propósitos o beneficios se derivarían del logro de la meta? (3).

Algunos autores las han llamado las preguntas $\mathrm{W}, \mathrm{W}, \mathrm{W}, \mathrm{W}, \mathrm{W}, \mathrm{W}$ en lugar de the six W questions, pero otros las llaman las preguntas $\mathrm{W}, \mathrm{W}, \mathrm{W}, \mathrm{W}, \mathrm{H}, \mathrm{W}, \mathrm{o}$ the five $W$ an one $H$ questions, colocando en quinto lugar el adverbio de modo interrogativo How (cómo) en lugar del pronombre interrogativo Which (cuál, cuáles), con el fin de especificar mejor el cómo, la manera, de alcanzar el objetivo.
Dr. Eugenio Matijasevic: Editor General Acta Médica Colombiana. Bogotá, D.C. (Colombia). E-mail: eugenio.matijasevic@gmail.com Recibido: 15/XII/2014 Aceptado: 15/XII/2014 
Por alguna razón, desde ese entonces, todos los administradores y gerentes con formación norteamericana dan por descontado que ese método de las seis preguntas para describir la especificidad de un objetivo se originó en Estados Unidos de América a partir de las desarrollos teóricos logrados por los autores norteamericanos de libros de managment.

Lo cierto, sin embargo, es que los periodistas consideran que la secuencia de preguntas mencionada constituye más bien un logro de su profesión y aseveran poseer una historia con mayor abolengo que la historia de los managers: Roy W. Howard, el periodista que el 7 de noviembre de 1918, cuatro días antes de la firma del armisticio de Compiègne que pondría fin a la Primera Guerra Mundial, diera la falsa primicia de que el acuerdo había sido ya firmado, y quien a pesar de ser el responsable de, como lo calificó el Times, "el más flagrante y culpable acto de engaño público en la historia del periodismo", continuaría como presidente de la United Press durante muchos años más (4), tenía como norma exigir a todos sus corresponsales y cronistas que siempre al comenzar un despacho noticioso, en el primer párrafo, dieran respuesta a las que él llamaba the five $W$ questions: "who did what, where and when, and why" (quién hizo qué, dónde y cuándo y por qué) (5). La mayoría de las escuelas de periodismo enseñan que estas preguntas conforman la base de toda noticia bien contada: si un periodista quiere asegurarse de que la noticia que difunde es inteligible para el público, independientemente del estilo propio de narrar el suceso y de los medios que haya utilizado para el efecto (por escrito, en sonidos o en imágenes), bastará con que pase revista y trate de responder con base en su relato o crónica a todas y cada una de estas preguntas. Si puede responderlas todas, es obvio que el lector, el oyente o el televidente podrán saber, con respecto al evento narrado, el autor, el lugar, el momento y los motivos.

Pero otro grupo norteamericano bastante prolífico también, el de los predicadores evangélicos de finales del siglo XIX, se atribuye tan sabia invención incluso desde antes que los periodistas norteamericanos: Henry Clay Trumbull, Doctor of Divinity de la Iglesia Congregacional, menciona "The five W's" en su libro Teaching and Teachers y refiere que todo profesor de catequesis debería utilizarlas como un método aliterativo para que en su plan de estudio de cada lección (antes de predicarla) no quedara por fuera ningún tema. Para Trunbull las cinco W eran: "When? Where? Whom? What? Why?", porque en el estudio de cada lección la atención se debe centrar sucesivamente en la fecha de los incidentes (When?), su lugar o ubicación (Where?), la persona que habla o a la que se dirige el narrador o la que es presentada en ese momento de la narración (Whom?), los incidentes o declaraciones del texto (What?) y, finalmente, las aplicaciones y empleos de las lecciones enseñadas. En Teaching and Teachers refiere además que la idea de ese plan de estudios no es de su autoría, sino que la derivó de W. C. Wilkinson para quien las W questions eran solo tres: "What?
Why? What of it?" en el sentido de que "primero [deben ir] los hechos; luego, la prueba de los hechos y, finalmente, las consecuencias de los hechos". Pero la idea original tampoco era de Wilkinson, Trumbull refiere que éste le contó que dicha expresión no era original suya sino que provenía de una venerable autoridad: “an almost immemorial orators's analysis" (un análisis de orador casi inmemorial) (6).

El "orador casi inmemorial" que menciona Wilkinson sin nombrarlo es nada más y nada menos que Tomás de Aquino, Doctor Angelicus de la Iglesia Católica, quien en su Summa Theologiae, en la primera sección de la segunda parte, en el artículo 3 de la cuestión 7, refiriéndose a las circunstancias (circumstantia: literalmente, lo que rodea-circum-algo que está allí, que permanece-stare-) que acompañan las acciones humanas, afirma que denomina circunstancia a todo aquello que, sin ser parte de la acción propiamente dicha, la afecta: "Y esto puede suceder de tres maneras: porque afecta al acto mismo, porque afecta a su causa o porque afecta a su efecto" (7), enunciado que se corresponde exactamente con las tres $W$ questions de Wilkinson. Pero las sorpresas que depara la lectura del Aquinate van más allá: un párrafo antes del fragmento mencionado, en el comienzo del artículo 3 de la cuestión 7, afirma que para Tulio (el nombre utilizado en la edad media para referirse a Marco Tulio Cicerón, a quien en la actualidad denominamos simplemente Cicerón) las circunstancias son siete, y que dichas circunstancias están contenidas en el verso "quis, quid, ubi, quibus auxiliis, cur, quomodo, quando" (8) (quién, qué, dónde, con qué medios, por qué, cómo, cuándo). En la versión inglesa de la Summa, en la traducción de The Fathers of the English Dominican Province, este verso es traducido como "Who, what, where, by what aids, why, how, and when" (9) palabras que se corresponden exactamente a the six $W$ questions, que en ese entonces, como podemos ver, no eran seis sino siete, por cuanto en el texto de Tomás de Aquino se agrega by what aids: con qué ayudas o por qué medios.

Ahora bien, Tomás de Aquino no afirma que el verso sea de Cicerón, sino que en el verso que cita están contenidas las siete circunstancias, según el Aquinate descritas por Cicerón en su en De Inventione Rhetorica, que deben establecerse alrededor de una acción humana si es que uno pretende describirla de manera completa. Sin embargo, el pretendido verso no se encuentra en De Inventione Rhetorica ni en ninguna de las obras de Cicerón. Tampoco encontramos el concepto claro y explícito de circunstancias, aunque en diversas partes de su obra, especialmente en De Inventio$n e$, se acerca a él como si de un viejo conocido se tratara, aunque sin nombrarlo. Una de dichas ocasiones tiene lugar al referirse a los medios por los cuales una narración se hace creíble: "si en ella parecen existir las cosas que suelen aparecer en la verdad; si se guardan las dignidades de las personas; si sobresalen las causas de los hechos; si parece que hubo facultades de hacer; si se muestra que el tiempo fue idóneo; que fue suficiente el espacio; que el lugar fue oportuno para la misma cosa, de la cual cosa se narra; si la 
cosa se acomoda tanto a la naturaleza de aquellos que actúan como a la costumbre del vulgo y a la opinión de aquellos que oyen" (10). Otra ocasión se da al referirse a las cosas que están siempre colindantes con una acción (negotium: lo que niega el ocio) y que no pueden separarse de ella, cuando dice que primero debe inquirirse por la causa de dicha acción: "a través de qué y por qué cosa y por causa de que cosa se hizo" y, más adelante, buscar "el lugar, el tiempo, el modo, la ocasión, la facultad" (11).

Con base en ese mismo hexámetro que cita Tomás de Aquino, el teólogo danés Agustín de Dacia desarrolló una técnica de meditación que le permitía a él y a sus discípulos analizar (y corregir) las desviaciones del alma con respecto al camino de la rectitud a lo largo del día (12).

Con ocasión del Cuarto Concilio de Letrán y duodécimo Concilio Ecuménico de la Iglesia Católica que tuvo lugar en 1215 convocado por el Papa Inocencio III, se declaró como obligatoria para todo cristiano la confesión al menos una vez al año y la comunión al menos una vez al año por la Pascua de Resurrección. Ese mismo concilio, en sus 71 cánones, condenó la herejía de los Cátaros y la de los Valdenses, sancionó una definición de eucaristía en la que por primera vez aparece la palabra transubstanciación, persiguió a los judíos obligándolos a utilizar ropas especiales e impidiéndoles el acceso a cargos públicos, organizó la Quinta Cruzada y condenó la Carta Magna (13). En su vigésimo primer canon el concilio estipulaba que los confesores debían buscar con diligencia "los pecados y las circunstancias de los pecadores" con el fin de sopesar con justicia las faltas confesadas y disponer los remedios oportunos. Fue precisamente para guiar a los confesores en su consideración de las circunstancias que rodeaban las acciones pecaminosas que se crearon diversos versos mnemotécnicos sobre las circunstancias en ese periodo de la edad media (14), pero ninguno corrió con tanta suerte y fama y difusión como el que cita Tomás de Aquino, quizás, también, por haberlo citado quien lo citó, aunque, muy probablemente, para la época en que él lo citó, el verso era ya lo suficientemente conocido como para que el Aquinate no citara la fuente o no pudiera citarla porque no la conocía y simplemente citó de memoria ese hexámetro aprendido tanto por él como por muchos de sus condiscípulos durante el proceso de aprendizaje del Trivium medieval (que incluía el estudio de la Gramática, la Dialéctica y la Retórica).

Su empleo en la confesión de los pecados deriva, posiblemente, de la propuesta de Boecio, con antecedentes en Cicerón, de utilizar las circunstancias en la constitutio iuridicialis, lo que en la actualidad llamaríamos "instrucción criminal", el momento en el que un reo debe ser interrogado con respecto al posible crimen y el encargado de administrar justicia debe iniciar la investigación de los hechos para determinar su naturaleza. Para Boecio cualquier pregunta con respecto a la naturaleza o al carácter de una cosa, es decir cuando se indaga sobre la cualidad o la cantidad de un hecho, se debe establecer si la indagación tiene que ver con el pasado, por una parte, o si tiene que ver con el presente o el futuro, por la otra. En el primer caso se denomina constitutio iuridicialis y en el segundo constitutio negotialis. Esta distinción también la establece Cicerón, pero para él la frontera se da entre aquellos casos en los que es necesario indagar por la naturaleza del hecho en cuanto a si es justo o injusto, en cuanto a las razones de la recompensa o de la Pena (constitutio iuridicialis), y aquellos casos en los que existe una controversia de derecho civil implícita en el hecho mismo que puede ser resuelta privadamente por las partes (constitutio negotialis) (15). Para Boecio la indagación indispensable en la constitutio iuridicialis puede ser de dos tipos, dependiendo del objetivo al que se enfoque la fuerza de la defensa: si ésta se dirige exclusivamente al hecho mismo la denomina qualitas absoluta, si la dirige hacia los aspectos externos al hecho la llama constitutio assumptiva. Es precisamente en este último caso en el que la indagación por las circunstancias resulta fundamental puesto que al tener en cuenta todas las que rodean una acción es posible establecer para cada acción la persona, la acción misma, el lugar, el momento, los motivos, la manera en que fue realizada y los auxiliares, por lo que para él las circunstancias son: "quis, quid, ubi, quando, cur, quomodo, quibus adminiculis" (quien, qué, donde, cuándo, por qué, cómo, con qué instrumentos) (16). La indagación por las circunstancias además, según Boecio, debe ser asumida por la Retórica, que se ocupa de hipótesis que tienen que ver precisamente con multitud de circunstancias, y no por la Dialéctica que se ocupa de tesis ajenas a las circunstancias.

Por su parte, el verso que cita Tomás de Aquino como que contuviese las ideas de Cicerón sobre las circunstancias, aunque sin afirmar que sea su autor, es un hexámetro, el tipo de verso utilizado en la poesía épica griega y latina (en él se escribieron La Iliada, La Odisea, La Eneida y Las Metamorfosis) y también en la poesía didáctica (en él escribió Lucrecio De Rerum Natura). Se llama hexámetro porque mide seis "pies", una medida de la métrica poética clásica que permite simultáneamente contar el número de sílabas y el ritmo en el que se suceden. Cada pié puede contener o bien dos sílabas largas (espondeo) o bien una sílaba larga y dos cortas (dáctilo). Un hexámetro clásico puede contener cualquier tipo de pié en los primeros cuatro pies, pero el quinto debe ser un dáctilo y el último un espondeo (17). Esta aliteración en el ritmo de las sílabas es lo que da al hexámetro la cadencia necesaria para que sea recordado con facilidad, de tal manera que los antiguos griegos y romanos no utilizaban frases mnemotécnicas basadas en la aliteración de letras iniciales, como los hablantes anglosajones actuales con sus six W questions, sino que utilizaban hexámetros de fácil recordación.

No se sabe a ciencia cierta quien inventó este hexámetro didáctico sobre las circunstancias. Antes que Tomás de Aquino lo citara hubo muchos intentos de descripción resumida de las circunstancias que rodean una acción dirigidos a facilitar su recordación pero ninguno de ellos tuvo tanto 
éxito como esta descripción breve y suscita que, además, viene en forma de hexámetro, facilitando así su aprendizaje.

El hexámetro se atribuyó por algún tiempo a Bernardo de Claraval, uno de los 33 doctores de la Iglesia Católica, apodado Mellifluous Doctor (boca de miel) por su elocuencia, predicador de la segunda cruzada, artífice de todo el poder y prestigio que alcanzó la Orden de los Caballeros del Temple, fundador de la Orden del Císter (18); pero en su obra no es posible encontrar el hexámetro, lo único parecido es una frase referida al nacimiento de Jesús en uno de sus sermones sobre la Navidad en la que recomienda "sopesar cuidadosamente los términos de este Adviento, preguntándose: ¿quién es el que viene? ¿de dónde viene? ¿de dónde es él ? ¿para qué viene? ¿cuándo? y ¿de qué manera?” (19). Lo cual comprueba que, aunque no sea Bernardo de Claraval el autor del hexámetro, el conocimiento de las circunstancias que rodean un hecho es muy útil en retórica al momento de planear o decir un discurso, en este caso un sermón sobre la Navidad.

También se ha atribuido el hexámetro a muchos otros autores de la Época Clásica y de la Edad Media, todos posteriores a Cicerón (quien no se refiere de manera específica a las circunstancias) y anteriores al Cuarto Concilio de Letrán (que las recomienda para la confesión de los pecados), desde Hermágoras de Temnos (contemporáneo de Cicerón y quien sí escribió de manera específica sobre las circunstancias) hasta Juan de Salisbury (c 1120-1180), pasando por Quintiliano (c. 35-c. 100 y Hermógenes de Tarso (h. 160-h. 225); pero en todos ellos, aunque es posible encontrar referencias más precisas que las de Cicerón al concepto de circunstancias, con enumeraciones de las mismas más o menos fáciles de recordar, brilla por su ausencia el hexámetro que cita Tomás de Aquino.

Es muy posible, como se dijo, que el hexámetro formara parte de una mnemotecnia propia de la enseñanza del Trivium y que no exista un único creador del mismo, sino que múltiples autores le hayan ido dando forma poco a poco, con el transcurrir de los años, hasta alcanzar su forma más perfecta y recordada. El autor más antiguo en el que ha sido posible constatar la presencia del hexámetro por escrito, aunque no es posible establecer que sea su autor, es Mateo de Vendome, quien en su Ars Versificatoria, escrito con toda seguridad antes de 1175 (cuarenta años antes del concilio de Letrán y casi un siglo antes de la Summa Theologiae), dice que los atributos tanto de una acción como de una persona están contenidos en ese verso, y cita el hexámetro para después agregar que este incluye el triple contenido de toda acción, es decir, antes del acto, durante el acto y después del acto, y que contiene, además, el lugar, los medios (la capacidad de realizar la acción), el por qué (la causa de la acción), el cómo (el modo o cualidad) y el cuando (el momento) $(20,21)$.

De todas maneras, Tomás de Aquino no se queda en la simple mención del hexámetro cuando se refiere a las circunstancias que rodean las acciones humanas, su concien- zudo análisis va mas allá y tiene que ver con otros conceptos relativos a las acciones humanas que no nos detendremos a analizar aquí, como los de libertad, voluntad, razón, deliberación y responsabilidad, que entroncan con otros filósofos que se han ocupado del problema de la acción. De hecho, después de glosar el hexámetro diciendo que "en toda acción humana se debe considerar quién lo hizo, con qué medios o instrumentos la ha ejecutado, qué es lo que ha hecho, dónde, por qué, cuándo y cómo lo hizo", Tomas de Aquino agrega que Aristóteles, en el tercer libro de la Ética a Nicómaco, añade otra consideración, otra circunstancia, que debe tenerse en cuenta de manera indispensable en toda acción humana: "acerca de qué", que, de acuerdo con su análisis, había quedado integrada por Cicerón en la circunstancia "qué". Con lo que the W questions no son tres como entre algunos predicadores Norteamericanos del siglo XIX, ni cinco como entre los periodistas Norteamericanos de comienzos del siglo XX, ni seis como entre los administradores de negocios Norteamericanos de fines del siglo XX, ni siete como entre los confesores católicos del siglo XIII y los maestros retóricos de los siglos previos a éste, sino ocho: quién, qué, dónde, cuando, cómo, con que medios, por qué (cuáles son sus causas) y acerca de qué o para qué (cuáles son sus fines). Si bien muchos incluyen en las causas de una determinada acción las metas o fines que con dicha acción se propone quien la lleva a cabo, Aristóteles en la Ética Nicómaco, en el marco de las acciones realizadas con responsabilidad y sin responsabilidad, establece una clara diferencia entre la causa eficiente (el por qué: "actué de tal manera porque....") y la causa final (el para qué: "actué de tal manera con el fin de...") y dice que no estaría mal determinar cuáles y cuantas son las circunstancias que rodean toda acción humana ya que conocerlas podría implicar, por parte de los demás habitantes de la Polis, la compasión o el perdón para quien ha llevado a cabo una acción deplorable. En un breve párrafo, refiriéndose por primera vez en la historia del pensamiento occidental a las circunstancias que rodean una acción, se da a la tarea de especificarlas: "quién hace y qué y acerca de qué o en qué, a veces también con qué, por ejemplo, con qué instrumentos, y en vista de qué, por ejemplo de ponerse a salvo, y cómo, por ejemplo, serena o violentamente" (22).

Las circunstancias relativas a toda acción humana han sido utilizadas como ya se mencionó, en administración de empresas, en periodismo, en clases de catequesis, en la retórica, en el sacramento de la confesión, en la instrucción criminal y en la cualificación moral de un acto, pero el que las posibilidades de su aplicación a tan diversos asuntos humanos sea tan extensa no corresponde a un capricho ni a la intención desbordada de alguien que quiere lograr que una fórmula prefigurada se acomode de manera forzada a un cierto hecho del mundo, por el contrario la aplicación a todos estos en apariencia disímiles sucesos ocurre de manera tan natural que nos vemos obligados a pensar que quizás la aparente magia del asunto no reside en la fórmula mágica sino en los asuntos a los que se aplica sin dificultad. De hecho 
todos ellos, bien mirados, pertenecen a una misma categoría de eventos del mundo: son eventos desencadenados por la intención de un ser con intencionalidad y a veces con razón y responsabilidad. En este sentido, una acción es un evento en el mundo cuyo origen atribuimos a la actividad de un agente racional en la medida en que éste puede dar una explicación del evento a partir de sus percepciones, creencias y deseos (que constituyen las razones o motivos para haber obrado así y no de otro modo) y existe una ruta causal que conecta ese evento del mundo con la intención del agente de haber actuado de ese modo (23). Los teóricos de la acción denominan explicación racional (a partir de razones o motivos) a este tipo de explicación para diferenciarla de las explicaciones causales (a partir de causas), y reservan el término "acción" para los eventos del mundo generados por agentes racionales de manera intencional y "suceso" para los eventos del mundo causados por otros eventos del mundo independientes de los agentes racionales o por agentes racionales que no los han generado de manera intencional $(24,25)$. Las preguntas por las circunstancias también pueden aplicarse a sucesos y a explicaciones causales pero sólo de manera parcial dado que, en tales casos, el “qquién?” que se aplica únicamente a personas, a seres a los que atribuimos razón (capacidad de dar explicaciones racionales), y el “¿para qué?” que se aplica únicamente a seres con intencionalidad, no pueden usarse sino con cierta licencia poética. Para hablar con propiedad del Huracán Katrina podemos utilizar el "¿qué?", “¿cuándo?”, ¿dónde?”, ¿cómo?”, ¿por qué?” y, forzando un poco el lenguaje, “con qué medios?”, pero no podemos usar el “quién?” ni el “¿para qué?” a no ser que pretendamos personificar al huracán en un campo que sería más el de la literatura fantástica que el de las explicaciones racionales.

¿Por qué un método mnemotécnico dirigido a recordar fácilmente las circunstancias que rodean un hecho de manera tan útil no se ha empleado en medicina? Si su utilidad ya ha sido demostrada en retórica, en literatura, en administración de negocios, en periodismo, en técnicas de estudio bíblico, en instrucción judicial de casos y en tantas otras empresas humanas, no se ve una razón para que en la medicina no nos hayamos beneficiado de semejante herramienta mnemotécnica. Pero la verdad es que sí, también en Medicina se han utilizado las siete "quaestionis" dirigidas a indagar sobre las circunstancias y se han utilizado precisamente en el sitio en el que deberían estar que no es otro que, como el lector ya habrá adivinado, en la anamnesis de la enfermedad actual. Quizás el desconocimiento de la utilidad de esta regla mnemotécnica en Medicina se deba a que su ámbito de aplicación fue, desde un comienzo, la homeopatía.

En efecto, en 1858 Clemens Maria Franz von Bönninghausen escribió un breve ensayo sobre el valor de los síntomas en la selección de un remedio homeopático (26). La historia es ésta: tres años antes, en el Gran Congreso Homeopático que había tenido lugar en Bruselas, Bönninghausen propuso a la sociedad de homeópatas que se concediera un premio al mejor ensayo que se escribiera en los dos años siguientes sobre el tema "el valor de los síntomas presentes en una enfermedad para ayudar como norma o base en la elección terapéutica de un remedio". La proposición fue aceptada, pero habían transcurrido ya tres años y nadie se había hecho merecedor al premio por la sencilla razón de que nadie había escrito en ese lapso un tratado sobre el tema propuesto. En su breve ensayo, Bönninghausen se queja del escaso interés por el asunto y vuelve a plantear el problema desde el comienzo, recordando que en en el parágrafo 153 del Organon del arte de curar, Samuel Hahnemann menciona que para la homeopatía uno de los puntos más importantes es establecer la yuxtaposición entre los fenómenos naturales de la enfermedad, la lista de los síntomas con los que se manifiestan las enfermedades y la lista de los medicamentos disponibles para cada síntoma con el fin de descubrir una potencia curativa correspondiente en magnitud al mal a ser curado (no es necesario recordar aquí la tesis principal de Hahnemann: similia similibus curantur -lo similar se cura con lo similar- o también similia similibus curentur -permitid que lo similar cure lo similar-). Es en este sentido que, para el padre de la homeopatía, deben establecerse de manera precisa cuáles son los síntomas más contundentes, peculiares, particulares y característicos de cada entidad mórbida con miras a ubicar el remedio homeopático con el efecto más preciso y era precisamente en esa dirección que Bönninghausen había propuesto el premio que nunca se dio. Bönninghausen no tiene tampoco la solución, pero considera que la mejor manera de iniciar la tarea de establecer la conexión síntomas-remedios que pide Hahnemann es, al menos, establecer de la manera más clara posible las características de cada síntoma que presente el paciente. Para lograr este cometido de una manera metódica, argumenta Bönninghausen, nada mejor que volver a la fórmula medieval "Quis? Quid? Ubi? Quibus auxiliis? Cur? Quomodo? Quando?”, aplicándola siempre en cada paciente a cada uno de sus síntomas. Bönninghausen consideraba que estas siete preguntas contenían todos los elementos esenciales para llevar a cabo una adecuada historia del caso y dedica el resto de su disertación a explicar el interés e impacto de cada pregunta en la descripción precisa de cada síntoma.

Debo recordar en este punto que la medicina alopática no existe. Ese fue un nombre que Hahnemann acuñó para referirse a la medicina que practicaban en su época quienes no estaban de acuerdo con él (y que, además, practicaban una medicina cuya terapéutica, basada en sangrías y purgas atroces, consideraríamos hoy tan inadecuada como la consideró entonces Hahnemann). Desde entonces los adeptos a la homeopatía utilizan ese nombre para referirse, de forma un tanto despectiva, a nuestra manera de cuidar, desde una perspectiva científica, a quienes sufren, manera que tiene una tradición que arranca desde la Escuela de Cos (aunque vale la pena aclarar que también los homeópatas consideran que su práctica posee raíces hipocráticas).

Siempre que los médicos nos referimos a la homeopatía nos apoyamos en argumentos que no admiten réplica para 
rechazar sus conclusiones y sus recomendaciones, entre dichos argumentos quizás el más socorrido ha sido que su terapéutica no tiene ninguna plausibilidad desde el punto de vista biológico ni físico en la medida que las diluciones recomendadas por Hahnemann permiten predecir, con base en una teoría científica tan simple como la de Avogadro, que no hay manera de que, por ejemplo, en el oscillococcinum, tan utilizado en la última década como remedio homeopático para la influenza y el resfriado común, haya una sola molécula del principio activo en el supuesto remedio que ingiere el paciente. El oscillococcinum es una disolución 200C del hígado de una variedad de pato oriunda de Francia; una dilución $200 \mathrm{C}$ implica tomar un volumen x del hígado del pato, diluirlo en 100 volúmenes $\mathrm{x}$ de agua destilada (a esto se refiere la $\mathrm{C}$ ), tomar de dicha dilución un volumen $\mathrm{x}$ y diluir esta alícuota en 100 volúmenes $\mathrm{x}$ de agua, tomar de nuevo un volumen $\mathrm{x}$ de esta segunda dilución y diluirla en 100 volúmenes de agua y continuar así 200 veces. De acuerdo con Avogadro (el número "mágico" de Avogadro es $6,022141 \times 10^{23}$ moléculas de cualquier sustancia por cada mol de la sustancia, es decir por una masa de la sustancia con un número igual de gramos al peso molecular de la sustancia en cuestión), en la dilución homeopática $14 \mathrm{C}$ es posible asegurar que, si la mezcla ha estado bien hecha, habrá una sola molécula en cada volumen de la dilución del hígado de pato, en la dilución 30C habría que tragarse una esfera con un diámetro igual a la distancia de la tierra al sol para garantizar que el paciente se toma una sola molécula del hígado de pato, en la dilución 40C habría que tragarse el universo entero (existen $10^{80}$ átomos en el universo observable), y a la dilución $200 \mathrm{C}$ no alcanzaría un universo como el conocido para contener una sola molécula del principio activo del remedio en cuestión (27).

De acuerdo con lo anterior los remedios no contienen el principio activo a las diluciones empleadas, y sin embargo son muchos seres humanos que siguen yendo en busca de los homeópatas. Alguien dirá que los buscan como se busca, como último recurso, in extremis, a todo tipo de magia omnipotente, en la medida en que cuando ya no hay esperanza un mecanismo de defensa es regresar a la magia infantil; sin embargo esa teoría no funciona del todo muy bien porque en el momento en que los pacientes constataran que la magia no funciona dejarían de ir al homeópata y, sin embargo, siguen yendo. Otros aseguran que los pacientes han sido embaucados, pero el contraargumento es el mismo, si el paciente percibe que lo han embaucado simplemente no regresa a que lo embauquen de nuevo, Pinocho no vuelve a hacer negocios den el gato y el zorro cuando se percata que las monedas de oro que sembró no retoñan ni crecen en el campo de la felicidad y que esos dos personajes le robaron su dinero; además los homeópatas no son embaucadores, ponen en práctica sus creencias de muy buena fe, es exactamente al revés: hay embaucadores que posan como homeópatas de la misma manera que hay embaucadores que posan como médicos o como banqueros o como administradores, etc., ese no es el problema. Tampoco sirve del todo el argumento del placebo, si así fuera los pacientes seguirían yendo también donde la vecina que les recomendó la infusión de toronjil o le preguntarían de nuevo a la mamá que les recetó miel con limón y no consultarían al homeópata; sin embargo, lo consultan y siguen consultándolo.

Algo deben estar haciendo bien los homeópatas fuera de recetar remedios inútiles, pues de no ser así los pacientes no los buscarían. Algo obtiene el paciente que los visita fuera de recibir sustancias inactivas. Bönninghausen construyó una práctica homeopática con más de 30000 pacientes a lo largo de su vida profesional (que entre otras cosas comenzó tarde, después de los 40 años) (28). Mi hipótesis para explicar este fenómeno, sin negar que algo hay de cierto en las demás (regresión infantil a la magia omnipotente, efecto placebo), es que están haciendo por el paciente lo que en ocasiones no hacemos nosotros: oírlo, atenderlo en el sentido profundo del término, cuidarlo aunque en un sentido restringido en la medida en que sus remedios carecen de plausibilidad, darle tiempo. Sería este el momento de tomarlos como ejemplo en cuanto a la relación médico-paciente y ofrecerles a nuestros pacientes no sólo lo mejor de la ciencia sino también lo mejor de nosotros mismos, nuestra capacidad para una interacción verdaderamente humana.

En resumen, deberíamos aprender de ellos y enseñarle a nuestros estudiantes esta regla: para cada síntoma que traiga el paciente recuerden hacer estas preguntas sobre las circunstancias, preguntas que la humanidad viene atesorando, recomponiendo y mejorando desde la Grecia clásica y que en la actualidad, en su forma más perfecta inquiere por: "quis, quid, ubi, quibus auxiliis, cur, quomodo, quando" (quién, qué, dónde, con qué medios, por qué, cómo, cuándo). "Quis?" pregunta por la persona, pero no pregunta por su identificación (nombre, documento de identidad, dirección, etc.) sino por el ser que sufre, por su vida, por su forma de vivir la vida y por su forma de estar en el mundo sobre todo desde una perspectiva que bien podríamos llamar emocional, mental o incluso anímica (¿qué quiere? ¿qué espera? ¿cómo busca lograrlo?). "Quid?" pregunta por el síntoma mismo, qué es lo que vive el paciente como una alteración en su estado habitual, como una alteración en el flujo cotidiano de sus percepciones y emociones. "Ubi?" indaga por la localización tanto del síntoma como del paciente, en dónde se localiza el síntoma, pero también en qué región anatómica vive el paciente, en qué medio geográfico, climático y social. "Quibus auxiliis?" averigua por cualquier elemento adicional que haya podido incrementar o atenuar el síntoma, incluyendo intentos terapéuticos previos. "Cur?" es la clave muy bien comprendida siempre del por qué, pero es siempre una hipótesis sobre el origen del síntoma aunque puede tratarse desde el punto de vista causal de algo tan evidente e inmediato como un traumatismo previo. "Quomodo?" interroga por el cómo del proceso sintomático, por la manera en que éste se presentó (agudamente, lentamente) y la manera como ha progresado, con atención especial a la 
interacción entre el síntoma y la evolución de la propia vida del paciente. "Quando?" se refiere al momento en el que comienza el síntoma desde el punto de vista de la historia temporal que todos compartimos (en tal fecha, a tal hora), pero también en qué momento de la vida del paciente, en qué momento de sus relaciones con la sociedad, con el trabajo, con su familia, con su propia vida.

\section{Referencias}

1. Doran GT. (1981). "There's a S.M.A.R.T. way to write management's goals and objectives". Management Review (AMA FORUM) 70 (11): 35-36.

2. Drucker P. The Practice of Mangement. New York: HarperBusiness; 2006: 416 pp.

3. Carpenter M, Bauer T, Erdogan B. Principles of Management, v. 1.0 [Internet]. Chapter 1.6 Your Principles of Management Survivor's Guide. Consultado el 4 de noviembre de 2014, Disponible en: http://catalog.flatworldknowledge.com/ bookhub/reader/5?cid=41991\&e=carpenter-ch01\#carpenter-ch01_s06

4. Bryk W. A False Armistice. The New York Sun 2004, noviembre 10. Consultado el 4 de noviembre de 2014. Disponible en http://www.nysun.com/on-the-town/ false-armistice/4596

5. Gergely T. Information et persuasion: Écrire. Tercera Edición. Bruselas: Éditions De Boeck Université; 2008; p 14.

6. Trumbull HC. Teaching and Teachers. Phildelphia: John D. Wattles Publisher; 1884: pp 120-121.

7. Tomás de Aquino. Suma Teológica. Tomo II. Martínez-Casado A (Traductor). Segunda Edición. Madrid: Biblioteca de Autores Cristianos; 1989: p 116.

8. Sancti Thomae de Aquino. Corpus Thomisticum. Summa Theologiae [33825] I'-IIae q. 7 a. 3 co. Textum Leoninum Romae 1891. Consultado el 4 de noviembre de 2014. Disponible en: http://www.corpusthomisticum.org/sth2006.html

9. Thomas Aquinas, St. The Summa Theologica [Internet]. Fathers of the English Dominican Province (Traductor). New York: Benziger Brothers; 1947. Consultado el 4 de noviembre de 2014. Disponible en http://www.intratext.com/IXT/ ENG0023/

10. Marco Tulio Cicerón. De la Invención Retórica. Reyes-Coria B (Traductor). México: Universidad nacional Autónoma de México; 1997: p 23.

11. Marco Tulio Cicerón. De la Invención Retórica I, 26. Reyes-Coria B (Traductor). México: Universidad nacional Autónoma de México; 1997: p 29.
12. Metcalfe M. Reading Critically at University. London: Sage Publications; 2006: pp 126-127.

13. Linebaugh P. Tehe Magna Carta Manifesto. Berkeley: University of California Press; 2008: pp 28-30

14. Robertson DW. A note on the classical origin of circumstances in the medieval confessional. Studies in Philology; 43 (1): 6-14.

15. Michel A. Les rapports de la rhetórique et de la philosophie dans l'oeuvre de Cicéron. París: Peeters France; 2003: p 479.

16. Magnano F. Il De topicis differentiis di Severino Boezio. Tesis de Doctorado. Universitá degli Studi di Salerno. Facoltà di Lettere e Filosofia Dipartimento di Latinità e Medioevo. 2008-2009. Consultada el 4 de noviembre de 2014 Disponible en http://elea.unisa.it:8080/jspui/bitstream/10556/268/1/tesi $\% 20 \% 20$ F.\%20Magnano.pdf

17. Halporn JW, Ostwald M, Rosenmeyer TG. The Meters of Greek and Latín Poetry. Indianapolis: Hackett Publising Co; 1994.

18. Evans GR. Bernard of Clairvaux. Oxford: Oxford University Press; 1999: pp $5-21$.

19. Bernard de Clairvaux. Sermons pour l'Année. Tome I.1: Avent et Vigile de Noël. In Adventu Domine. Sermo Primus. De Sex Circumstantiis Adventus. 162: 20-26. Paris: Les Éditions du CERF; 2004: p 97.

20. Matthew of Vendôme. Ars Versificatoria (The Art of the Versemaker). Parr RP (Traductor). Milwaukee, Wisconsin: Marquette University Press; 1981: p 59.

21. Mathei Vindocinensis. Opera Vol III. Ars Versificatoria. Munari F (Editor). Roma: Edizioni di Storia e Letteratura; 1988: p 128.

22. Aristóteles. Ética a Nicómaco. Araújo M, Marías J (Traductores). Madrid: Centro de Estudiios Políticos y Constitucionales; 2002: p 34.

23. Strawson PF. Analysis and Metaphysics: An Introduction to Philosophy. Oxford, Oxford University Press; 1992. p 135.

24. Von Wright, Georg Henrik. Explanation and Understanding. Ithaca: Cornell University Press; 1971: 74-125.

25. Davidson D. Actions, reasons and causes. En: Essays on Actions and Events. Oxford: Oxford University Press; 2001: pp 3-20.

26. Bönninghausen von CMF. A Contribution to the Judgement Concerning the Characteristic Value of Symptoms. En: Lesser Writings. Braseros TL, Taffel LH (Editores). New Delhi: B. Jain Publishers; 2005: pp 105-129.

27. Singh S, Ernst E. Trick or treatment?. New York: W. W. Norton \& Company; 2009: pp 91-144.

28. Baschin M. How patients built up the practice of the lay homeopath Clemens von Bönninghausen CMF. Quantitative and qualitative aspects of patient history. Dynamis 2011; 31 (von 2): 475-495 